\title{
Rod derotation technique, a good option for correction of idiopathic kyphoscoliosis
}

\author{
Md. Anowarul Islam, Santosh Batajoo and Manish Shrestha
}

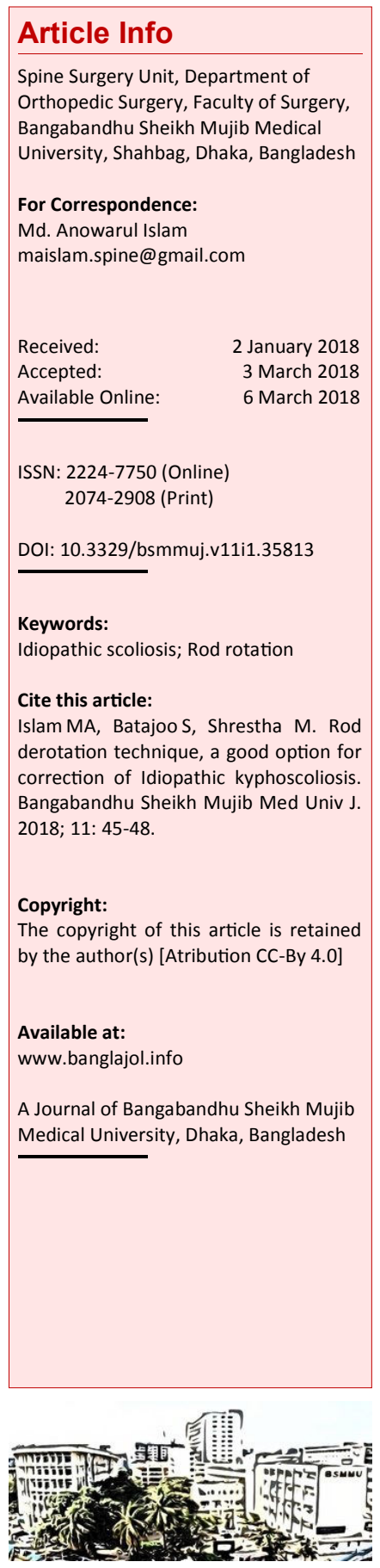

\section{Abstract}

Review of the radiological and clinical outcomes of the correction of idiopathic scoliosis by convex rod rotation were done in this prospective interventional study. Axial translation technique with pedicle screw-rod was used for correction of scoliosis. 35 patients (10 males, 25 females) were studied on the basis of clinical and radiological outcomes with a mean age of 14.8 years and follow -up a period of 32.5 months. Placement of screws was more on the concavity, around apical region and instrumentation at all levels were not mandatory. Radiological evaluation was done preoperatively and at 1, 3, 6 and 12 months post-operatively by whole spine standing anteroposterior, lateral radiographs and yearly thereafter. Spinal balance was noted, measurement of Cobb's angles, SRS questionnaire for clinical evaluation and complications were documented. The study result shows three-dimensional deformity of spine can be corrected effectively with simple rod rotation with pedicle screw instrumentation by axial translation technique.

\section{Introduction}

Idiopathic scoliosis is a three dimensional deformity including lateral deviation in the coronal plane, kyphosis or lordosis in the sagittal plane with rotation in the transverse plane. Correcting system with optimal correction and rigid fixation with minimum fusion are considered ideal. Moreover, it should correct all three dimensions of the deformity.

Harrington instrumentation used hooks in the upper and lower stable vertebra and compression distraction forces is used for the correction. This system was used as a treatment of choice for scoliosis for many years. But, Harrington instrumentation is not helpful in correction of coronal plane and flat back deformity was also a major complication. Harrington instrumentation is no longer regarded as the treatment of choice for scoliosis surgery. $\underline{1}$

Rotational deformity and coronal angulations are better corrected by other techniques than the Harrington system. Rotation occurs mostly in the apical vertebrae, but also in other vertebrae. Both deformities can be corrected by pedicle screws.? Cotrel-Dubousset instrumentation has helped in adequate reduction in the frontal plane as well as in the sagittal and transverse planes. This instrumentation system has been accepted by most surgeons. 3 With the experience of Cotrel-Dubousset system, universal spine system $\underline{4}$ was developed where the instability of Cotrel-Dubousset system occurring above and below the construct was balanced by the frame created by rods and screws fixed at the cranial and caudal end. Translation of anchor points of intervening segments into the construct was done using axial translation technique. This system also allows active derotation in each segment, correction of thoracic kyphosis and convex rib deformity.

This study shows that rod derotation technique using universal spine system with axial translation technique is a good option for the correction of idiopathic kyphoscoliosis.

\section{Materials and Methods}

Posterior correction of scoliosis with pedicle screw construct by the rod derotation technique was performed in 35 patients (10 males and 25 females) from January 2012 to December 2017. The average age was 14.8 years (range 11 to 24 years). The indication for surgery was Cobb's angle of $40^{\circ}$ or more but less than $90^{\circ}$. Data sheets and investigations including $\mathrm{X}$-ray, magnetic resonance imaging (MRI), computer tomography (CT) scan and lung spirometry were done. The average follow-up period was 32.5 months (range 10 to 48 months). Standing antero-posterior and lateral views with supine right and left bending antero-posterior views and traction films X-ray were done pre- 

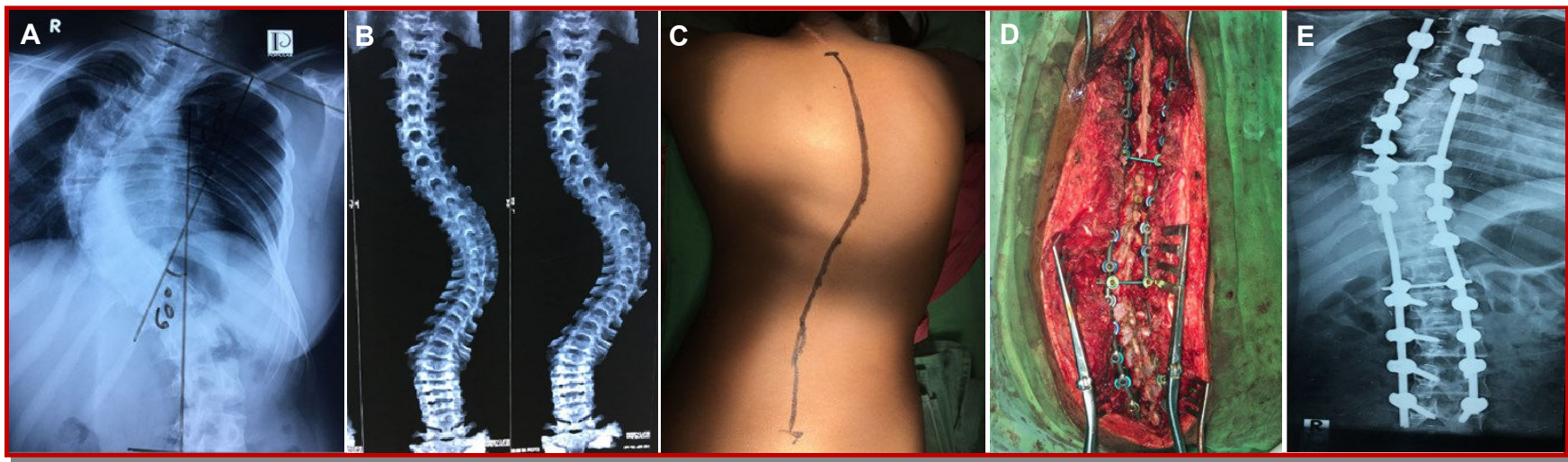

Figure 1: (A) Pre-operative X-ray whole spine anteroposterior view shows the cobb's angle (60 degree) as well as apex vertebra; (B) Preoperative CT scan of whole spine coronal section shows the position of pedicle; (C) Per-operative skin marking over the spinous process of desired incision; (D) Per-operative image shows screw and rod placement with deformity correction; (E) Post-operative X-ray whole spine anteroposterior view shows the pedicle screw and rod with degree of correction of cobb's angle

operatively. During post-operative follow-up period, the whole spine standing antero-posterior and lateral view X-ray were taken and at 6 and 12 months then annually. Cobb's angle, thoracic sagittal profile- T5-T12, C7 plumb line, apical vertebral translation and apical vertebral rotation (Nash-Moe grading) were recorded. The upper and lower levels of instrumentation and levels of instrumentation were recorded. Signs of fusion, instrumentation failure and pseudoarthrosis were noted in the post-operative radiographs.

\section{Results}

The average pre-operative and post-operative Scoliosis Research Society (SRS) scores are shown in Table I. Self image and satisfaction domain were improved, which had most impact after surgical intervention. Increment in the SRS score from 3.4 to 4.1 showed significant improvement where it got better from 68.6 to $82.2 \%$. The most frequent pattern of involvement was King type III (62.5\%) followed by King type II (59.9\%). Radiographic measurements were taken pre-operative, immediate post- operative and the last follow-up Cobb's angle. The pre-operative, post-operative and final follow-up Cobb's angle are also shown in Table I where the mean pre-operative Cobb's angle was 61.8 degree, immediate post-operative $\mathrm{Cobb}^{\prime}$ s angle was 16.7 and the final follow-up 18.9. The loss of correction ranged from 1 to 3 degree with mean correction of $69.9 \%$. One patient had superficial infection and 15 pedicle screws were malpositioned in three of the cases. Out of these three cases, two had implant failure who later underwent revision surgery. The study results showing the distribution according to King classification of scoliosis and pre-operative, post-operative, Cobb's angle at final follow-up along with SRS score are shown in Table I.

\section{Complications}

Superficial infection was noted in one case and was managed with the regular dressings and antibiotics. Among the 630 screws, 15 screws were malpositioned and two of the cases had implant failure who later underwent revision surgery (Table II). Neurological deterioration was not observed in any of our cases. Long-term complication was not found.

\begin{tabular}{|c|c|c|c|c|c|c|c|}
\hline \multicolumn{8}{|c|}{ Table I } \\
\hline \multicolumn{8}{|c|}{$\begin{array}{l}\text { Cases according to the King's classification of AIS with preoperative, immediate postoperative and final follow-up } \\
\text { Cobb angle and SRS score }\end{array}$} \\
\hline King & $\begin{array}{l}\text { No. of } \\
\text { cases }\end{array}$ & $\begin{array}{c}\text { Pre-operative } \\
\text { Cobb }\end{array}$ & $\begin{array}{c}\text { Post-operative } \\
\text { Cobb }\end{array}$ & $\begin{array}{c}\text { Final follow- } \\
\text { up }\end{array}$ & Correction & $\begin{array}{l}\text { SRS pre- } \\
\text { operative }\end{array}$ & $\begin{array}{l}\text { SRS final follow- } \\
\text { up }\end{array}$ \\
\hline I & 1 & 54 & 14 & 16 & 70.4 & 3.2 & 4.2 \\
\hline II & 8 & 59.9 & 15.3 & 17.5 & 71 & 3.3 & 4.1 \\
\hline III & 22 & 62.5 & 17.4 & 19.5 & 68.9 & 3.4 & 4.1 \\
\hline IV & 3 & 64 & 18 & 20 & 71.8 & 3.5 & 4 \\
\hline V & 1 & 62 & 12 & 14 & 77.4 & 3.2 & 4.1 \\
\hline Average & $\mathrm{n}=35$ & 61.8 & 16.7 & 18.9 & 69.9 & 3.4 & 4.1 \\
\hline
\end{tabular}




\begin{tabular}{|lr|}
\hline \multicolumn{2}{|c|}{ Table II } \\
\hline Number of cases of complication of surgery \\
\hline Complications & Cases \\
\hline Superficial infection & 1 \\
Malplaced screws & 3 (15 screws) \\
Implant failure & 2 \\
Neurological & 0 \\
\hline
\end{tabular}

\section{Discussion}

Adult idiopathic scoliosis being the most common subtype consists of deformity in three planes i.e., coronal, sagittal and axial planes. Lateral deviation occurring in coronal plane, kyphosis or lordosis on sagittal plane and rotation of vertebra on axial plane. The coupling deformities of these planes signifying that deformity in any one of the planes does not occur in isolation. 5,6 Clinical assessment was done using the SRS score. 30 outcomes questionnaire which included 5 domains- pain, function, self-image, satisfaction and mental health. Major changes were noted in the domains of selfimage and satisfaction and the other three domains did not show much change post-operatively and at the final follow-up. Our series showed improvement of SRS scores with average of $13.6 \%$ at last follow-up which is better to the $7.1 \%$ quoted in the series of Lehmann et al. (2008). .7 Comparative analysis between the pedicle screw and hybrid instrumentation published by Kim et al. (2006) showed that the hybrid group was 56 and $70 \%$ average major curve correction in the screw group and which is similar to our study which is $69.9 \% .8$ We did not use hybrid construct with hooks and pedicle screws were not kept in all levels. Moreover, screws were placed more in the concavity and in the periapical region. The correction of the curve approximately matched those found by other authors. Other recent techniques of curve correction are direct vertebral rotation and vertebral coplanar alignment.

Correction of $79.6 \%$ showed in the study by Suk et al. (2005) 9 using the technique of direct vertebral rotation. In that study, pedicle screws are put in the concavity of vertebral deformity and a contoured rod is fitted into them followed by standard counter -clockwise derotation technique. $73 \%$ curve correction as showed by Vellespir et al. (2008) 10 with the technique of vertebral coplanar alignment. In our study, we were able to achieve a correction of $69.9 \%$ which shows similar results compared to these two recent techniques. Probability of pedicle screw malpositioning is high in scoliosis correction surgery than other surgeries. Misplaced screw were $1.7 \%$ in 311 screws in Di Silvestre et al. (2007) 11 and Kuklo et al., (2002)르 could show an accuracy of
96.3\%. Three cases (15 screws) had malpositioned screws which is $2.4 \%$ and is comparable to the above study.

\section{Conclusion}

Spinal instrumentation systems, using the axial translation technique by pedicle screw and rod, achieved good clinical and radiological outcome for the patients of adolescent idiopathic scoliosis.

\section{References}

1. Lee SM, Suk SI, Chung ER. Direct vertebral rotation: A new technique of three-dimensional deformity correction with segmental pedicle screw fixation in adolescent idiopathic scoliosis. Spine 2004; 29: 343-49.

2. Modi HN, Suh SW, Srinivasalu S, Mehta S, Yang $\mathrm{JH}$. Comparison of apical axial derotation between adolescent idiopathic and neuromuscular scoliosis with pedicle screw instrumentation. Asian Spine J. 2008; 2 : 74-80.

3. Delorme S, Labelle H, Aubin CÉ, de Guise JA, Rivard $\mathrm{CH}$, Poitras B, Coillard C, Dansereau J. Intraoperative comparison of two instrumentation techniques for the correction of adolescent idiopathic scoliosis: Rod rotation and translation. Spine 1999; 24: 2011-18.

4. Laxer E. A further development in spinal instrumentation. Eur Spine J. 1994; 3: 347-52.

5. Kuklo TR, Potter BK, Lenke LG. Vertebral rotation and thoracic torsion in adolescent idiopathic scoliosis: What is the best radiographic correlate? J Spinal Disord Tech. 2005; 18: 139-47.

6. Plaza CA, Karsaclian M, Rocca C. Segmental scoliosis correlation: Use of the Lea Plaza Frame. Spine 2004; 29: 398-404.

7. Lehman Jr RA, Lenke LG, Keeler KA, Kim YJ, Buchowski JM, Cheh G, Kuhns CA, Bridwell KH. Operative treatment of adolescent idiopathic scoliosis with posterior pedicle screw-only constructs minimum three-year follow-up of one hundred fourteen cases. Spine 2008; 33: 1598-604.

8. Kim YJ, Lenke LG, Kim J, Bridwell KH, Cho SK, Cheh G, Sides B. Comparative analysis of pedicle screw versus hybrid instrumentation in posterior spinal fusion of adolescent idiopathic scoliosis. Spine 2006; 31: 291-98.

9. Suk SI, Lee SM, Chung ER, Kim JH, Kim SS. Selective thoracic fusion with segmental pedicle screw fixation in the treatment of thoracic idiopathic scoliosis more than 5-year follow-up. Spine 2005; 30: 1602-09.

10. Vallespir GP, Flores JB, Trigueros IS, Sierra 
EH, Fernández PD, Olaverri JC, Alonso MG, Galea RR, Francisco AP, Rodríguez de Paz B, Carbonell PG, Thomas JV, López JL, Paulino JI, Pitarque CB, García OR. Vertebral coplanar alignment: A standardized technique for three dimensional correction in scoliosis surgery: Technical description and preliminary results in Lenke type 1 curves. Spine 2008; 33: 1588-97.

11. Di Silvestre M, Parisini P, Lolli F, Bakaloudis G.
Complications of thoracic pedicle screws in scoliosis treatment. Spine 2007; 32: 1655-61.

12. Kuklo TR, Lenke LG, Graham EJ, Won DS, Sweet FA, Blanke KM, Bridwell KH. Correlation of radiographic, clinical, and patient assessment of shoulder balance following fusion versus nonfusion of the proximal thoracic curve in adolescent idiopathic scoliosis. Spine 2002; 27: 2013-20. 